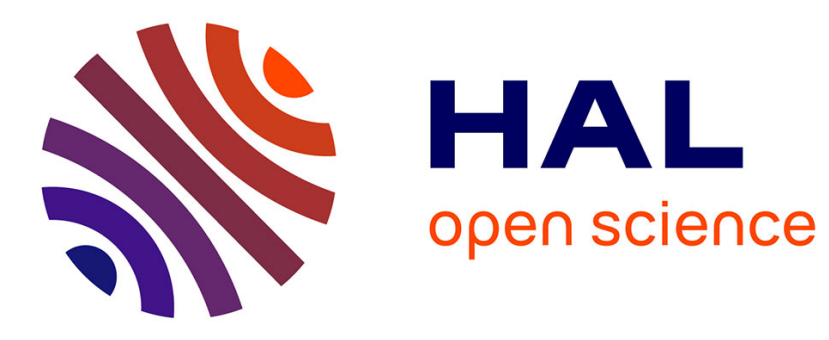

\title{
High Electric Field and Energetic Processes in Poly(ethylene naphthalate)
}

G. Teyssedre, Christian Laurent, Laurent Boudou, Séverine Le Roy

\section{To cite this version:}

G. Teyssedre, Christian Laurent, Laurent Boudou, Séverine Le Roy. High Electric Field and Energetic Processes in Poly(ethylene naphthalate). 2019 2nd International Conference on Electrical Materials and Power Equipment (ICEMPE), Apr 2019, Guangzhou, China. pp.85-90, 10.1109/ICEMPE.2019.8727251 . hal-02340318

\section{HAL Id: hal-02340318 https://hal.science/hal-02340318}

Submitted on 2 Dec 2020

HAL is a multi-disciplinary open access archive for the deposit and dissemination of scientific research documents, whether they are published or not. The documents may come from teaching and research institutions in France or abroad, or from public or private research centers.
L'archive ouverte pluridisciplinaire HAL, est destinée au dépôt et à la diffusion de documents scientifiques de niveau recherche, publiés ou non, émanant des établissements d'enseignement et de recherche français ou étrangers, des laboratoires publics ou privés. 


\title{
High Electric Field and Energetic Processes in Poly(ethylene naphthalate)
}

\author{
G. Teyssedre, C. Laurent, L. Boudou, S. Le Roy \\ LAPLACE, Université de Toulouse, CNRS, UPS, INPT \\ 118 route de Narbonne \\ 31062 Toulouse, France
}

\begin{abstract}
Poly(ethylene naphthalate) is a semi-crystalline polymeric material having high field withstanding and strong luminescence properties owing to its aromatic structure. Because of these two features it is the insulating polymer having strongest electroluminescence -EL yield investigated so far. EL is detected in an electric field regime where strong non-linear conduction properties have been identified. The light excitation mechanism, though not completely elucidated could be charge recombination with a contribution from impact excitation. It is believed that copious space charges effects are at play in the field regime when EL is detected. The EL spectrum shape evolves with field and some of the bands were ascribed to electrical ageing of the material. All of these features make of PEN a fascinating model material for investigating fundamental processes at play under high fields in insulating polymers.
\end{abstract}

\section{INTRODUCTION}

Poly(ethylene 2,6-naphthalate) -PEN is an unsaturated polyester structurally similar to the most commercially important polyester PET - Poly(ethylene terephthalate) [1]. PEN is competitive with PET in certain performance-driven markets based on its superior strength, heat stability and barrier properties to gases [2].

Whereas PET is widely and even massively produced for many applications ranging from textile, to packaging and to capacitors, PEN is relatively newer, more expensive such that its superior properties are not necessarily exploited. Replacing a phenyl ring by a naphtyl ring, cf. Fig. 1, has some consequences on the mechanical properties, making the polymer chain stiffer [1] and leading in general to a shift to higher temperature of characteristic transitions. It also has a great impact on the photo-physical properties of the material, PEN being a very efficiently luminescent material. Many recent studies focus on the application of PEN to scintillators for radiation detection [3, 4]. Detailed investigations of the optical properties of PET and PEN were reported by spectroscopic ellipsometry, in terms of their optical, electronic, and vibrational response and with consideration of anisotropic response in bioriented films [5].

From the dielectric properties point of view, Ohki et al. [6] made recently a comparative study on the (low field) dielectric properties of PET and PEN: due to similar chemical structures, PET and PEN have many parallel dielectric properties mainly controlled by an increase by about $50^{\circ} \mathrm{C}$ (from $\approx 70$ to $\approx 120^{\circ} \mathrm{C}$ ) [7] of the glass transition temperature. Both are polar materials, producing relatively high dielectric losses in a given frequency range $[6,7]$.

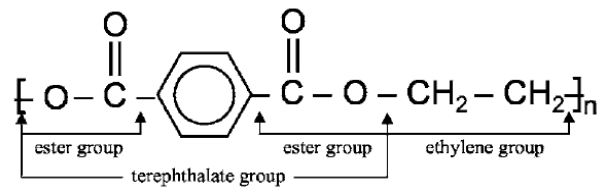

(a)

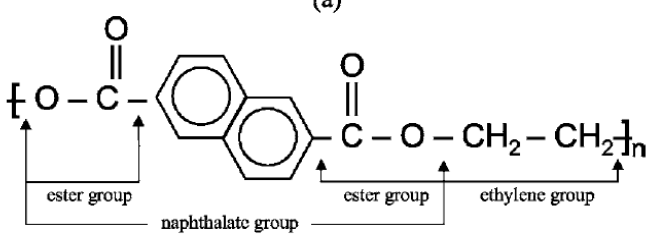

(b)

Fig. 1. Molecular structure of the (a) poly(ethylene terephthalate) -PET and (b) poly(ethylene naphthalate) - PEN [5].

We have investigated the high field behavior of PEN over the last 20 years, considering especially its electroluminescence properties [8-11]. Indeed, owing to its high luminescence yield, strong non-linear behavior at high field and high field withstanding, it has been considered as a model material for electroluminescence analysis. Our purpose in this communication is to review the behavior of PEN under high electric field in relation to its photo-physical properties.

\section{Structure AND OpticAl Properties OF PEN}

\section{A. Microstructure and dynamics}

PEN is a semicrystalline material that can be easily obtained in a broad range of crystalline degree, ranging from purely amorphous to $\approx 60 \%$ crystallinity by thermal annealing. The glass transition temperature $\mathrm{T}_{\mathrm{g}}$ is at about $125^{\circ} \mathrm{C}$, and the melting point at about $270^{\circ} \mathrm{C}$. Upon heating of amorphous material, cold crystallization occurs in the range $160-180^{\circ} \mathrm{C}$ [12].

For PEN, four relaxation peaks (labelled $\beta, \beta^{*}, \alpha$ and $\rho$ ) have been reported by using different experimental techniques (Dielectric Electrical Analysis, Dynamic Mechanical Analysis or Thermally Stimulated Depolarization Current). Fig. 2 shows an example of relaxation map obtained by impedance spectroscopy [13].

The $\beta$ relaxation, which is observed at the lower temperature, is assigned to the local motion of ester groups $(\mathrm{O}-\mathrm{C}=\mathrm{O})$ of the polymer chain [13-15]. For Hakme et al. [16], the asymmetric shape of the $\beta$ relaxation is due to the overlapping of two symmetric relaxations $\beta_{1}$ and $\beta_{2}$, which 


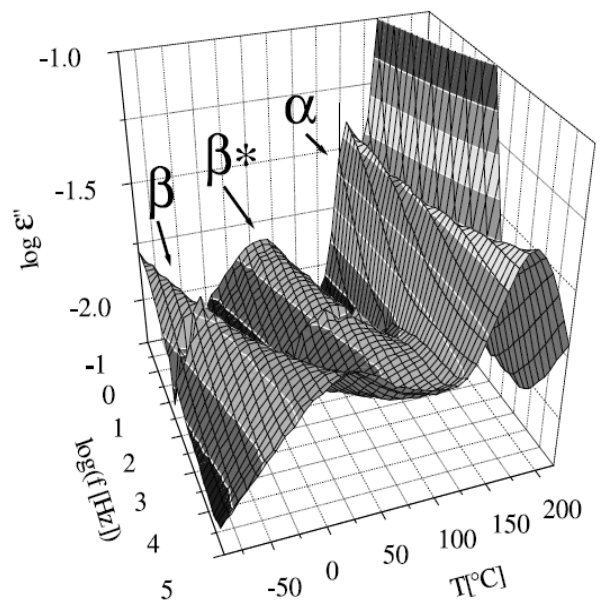

Fig. 2. Dielectric loss factor map of biaxially oriented PEN heat-treated at $250^{\circ} \mathrm{C}$ showing the 3 relaxation processes: $\beta, \beta^{*}$ ad $\alpha$. From [13].

amplitudes strongly depend on the humidity content, the drawing ratio and the stretched temperature. The $\beta^{*}$ relaxation, observed at a temperature between the $\beta$-peak temperature and $\mathrm{T}_{\mathrm{g}}$, is related to the relative motion of the two parts of the naphtyl ring or is thought to be due to the presence of COOgroups adjacent to the naphtyl ring in different configurations $[17,18]$. The $\alpha$ relaxation is clearly related to the glass transition of PEN, involving long-range cooperative segments motion. Finally the interpretation of the $\rho$ peak, observed at a temperature higher than $\mathrm{T}_{\mathrm{g}}$, is more difficult. For MartinezVega et al. [19] the $\rho$-peak is linked to the cold crystallization process. For Canãdas et al. the $\rho$-peak is directly linked to the rearrangement of the amorphous-crystalline interphases, which can act as traps for charges [12]. Hoang et al. [20], by coupling TSDC and space charge measurements, concluded that the $\rho$-peak is predominantly associated with the release of the negative charges trapped in the material, associated with a structural change due to an annealing phenomenon.

\section{B. Optical and electronic properties}

The existence of a naphtyl group in PEN, instead of the phenyl ring in PET, leads to a significant shift of the characteristic absorption bands to lower energies, as well as a characteristic split in all of them [5]. The main absorption peaks of PEN in the UV-vis region are found at $\approx 3.4 \mathrm{eV}$ (365 $\mathrm{nm}), 3.6 \mathrm{eV}(345 \mathrm{~nm}), 4.3 \mathrm{eV}(290 \mathrm{~nm})$ and $5.1 \mathrm{eV}(240 \mathrm{~nm})$. The 2 lowest energy peaks are attributed to the electronic transition of the non-bonded electron of the carbonyl $\mathrm{O}$ atom from the $\mathrm{n}$ state to the $\pi^{*}$ unoccupied valence state orbital $(\mathrm{n} \rightarrow$ $\pi^{*}$ transition). The other two peaks are splitted in three components each and correspond to the electronic transition due to the $\pi \rightarrow \pi^{*}$ excitation of the $\pi$-electron structures. Because of these features, the PEN films are strongly absorbing: for a $25 \mu \mathrm{m}$ thick film, all the light is absorbed under 380 nm, see Fig. 3 [10].

The photoluminescence spectrum of PEN has been reported in different works [8-10]. At room temperature, the fluorescence emission shows a peak at $430 \mathrm{~nm}$, irrespective of the excitation wavelength: the spectrum remains strictly

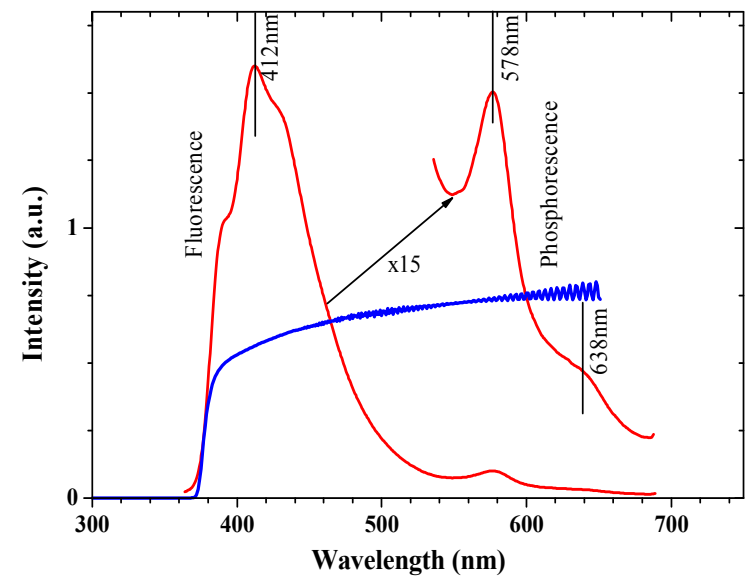

Fig. 3. In blue: UV-vis absorption spectrum of a $25 \mu \mathrm{m}$ thick PEN film [10]. In red: Photoluminescence spectrum of PEN measured at $-110^{\circ} \mathrm{C}$. The phosphorescence region is magnified for clarity. From [9].

unchanged when exciting in the range 220-360 nm [10]. Fig. 3 shows an example of spectrum obtained at low temperature (about $-110^{\circ} \mathrm{C}$ ) [9]. The fluorescence exhibits a structured emission with bands at 390,412 and $430 \mathrm{~nm}$. It has been associated to a ${ }^{1}\left(\pi, \pi^{*}\right)$ fluorescence transition of an excimer state formed between two adjacent naphthalene-dicarboxylate units [21-23]. A weak phosphorescence emission, not detected at room temperature, is visible in Fig. 3 with peaks at 578 and $638 \mathrm{~nm}$. The emission has been assigned to a ${ }^{3}\left(\pi, \pi^{*}\right)$ phosphorescence transition originating from the monomeric units $[22,24]$. The low yield of PEN phosphorescence is due to a low probability of intersystem crossing between ${ }^{1}\left(\pi, \pi^{*}\right)$ and ${ }^{3}\left(\pi, \pi^{*}\right)$ states as detailed in [24].

The various transitions and energy band diagram for PEN are represented in Fig. $4[8,9]$. The relative positions of the energy levels are from quantities given above, considering particularly data from Cheung et al. [24].

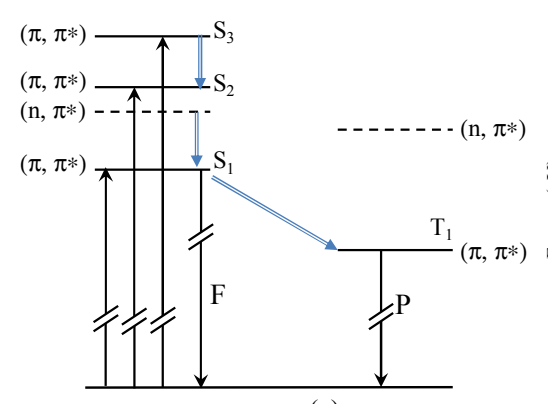

(a)

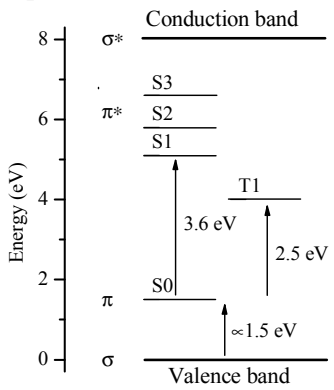

(b)
Fig. 4. (a) The electron transitions for dimethyl 2,6-naphthalene dicarboxylate in ethanol solution (taken from [24]). (b): Tentative energy band diagram for dimethyl 2, 6-naphthalene dicarboxylate. The order of magnitude of the energy gap has been inferred on the basis of the transition $\sigma \rightarrow \sigma^{*}$ of $\mathrm{C}$ atoms.

\section{ELECTRICAL PROPERTIES}

\section{A. Current-voltage characteristics}

PEN is a polar material, as manifested by the large amplitude of relaxation peaks shown in Fig. 2. For this reason, reaching conduction current is not a straightforward task as the transient current is dominated by polarization contributions (see below). Long charging times are needed to avoid 
orientation current, but charge build up can be at play. Indeed, in the high field range, $300 \mathrm{kV} / \mathrm{mm}$ or so, evidence of massive space charge build was reported with a continuous decrease of the charging current over days [25]. Chavez et al. investigated the field dependence of conductivity for PEN with various degrees of crystallinity as obtained with 'intermediate' charging times of $2 \mathrm{~h}$ at each voltage level, cf. Fig. 5 [26]. A ohmic regime is evidenced up to about $80 \mathrm{kV} / \mathrm{mm}$. As shown below, a second change in conduction regime occurs at about $140 \mathrm{kV} / \mathrm{mm}$ [27]. Surprisingly the crystallinity does not influence much the resistivity with a variation by a factor of less than 2 between the two extreme values in the ohmic region ( 2.9 vs. $\left.5.710^{16} \Omega . \mathrm{m}\right)$.

\section{B. Polarization and space charges}

Space charges were measured on PEN in very different conditions and using different methods. Because PEN is polar, and owing to the slow release of dipoles in the glassy state, the space charge measured in volt-off contains a response due to orientation polarization [20, 27]. By laser-induced pressure pulse -LIPP measurements on relatively thin samples $(50 \mu \mathrm{m})$, homocharges were detected near the both electrodes, in similar amount, for fields in the range $100-225 \mathrm{kV} / \mathrm{mm}$. By lightinduced modulation method -LIMM similar space charge profiles with homocharges at both electrodes were detected in $25 \mu \mathrm{m}$ thick films under $200 \mathrm{kV} / \mathrm{mm}$, cf. Fig. 6 [28, 29]. Fukuma et al. [30] investigated transient charge processes by pulsed electro-acoustic -PEA method in $75 \mu \mathrm{m}$ thick PEN films under ramped/square signal with various rising rate, at fields up to $200 \mathrm{kV} / \mathrm{mm}$. Here negative charges were dominant, in high density - of the order of $50 \mathrm{C} / \mathrm{m}^{3}$, and occupied the all thickness, cf. Fig. 7. Most of the charges appeared to be released quickly but transient processes in EL and charge measurements during voltage rising revealed the presence of stored positive charges near the electrodes. All the above experiments were carried out at room temperature. More recently Hoang et al. [20] carried out space charge measurements by PEA after previously charging the film (188 $\mu \mathrm{m}$ thick) at $170^{\circ} \mathrm{C}$ under a field of $10 \mathrm{kV} / \mathrm{mm}$. After cooling, the space charge is frozen. The charge profile appears dominated by negative charges occupying the volume. For a polarization temperature of $130^{\circ} \mathrm{C}$ no charges were detected.

\section{ElectroluminESCENCE PROPERTIES}

\section{A. Electroluminescence under DC stress}

The EL-field and current-field characteristics can be recorded simultaneously under DC stress using a home-made set-up [8]. Example of such results is given in Fig. 8. Here a step-up voltage was applied, keeping relatively short time (5min) at each step in an objective to limit charge build up into the material. Once the maximum field of $300 \mathrm{kV} / \mathrm{mm}$ was reached the field was stepped down with 2.5 min duration at each step. During stepping up the stress, a clear threshold for EL detection is found at about $140 \mathrm{kV} / \mathrm{mm}$. The current rises sharply beyond the threshold for EL detection. Beyond the field threshold, the EL appears proportional to the applied field and it is such over 5 decades in signal [9]. When stepping

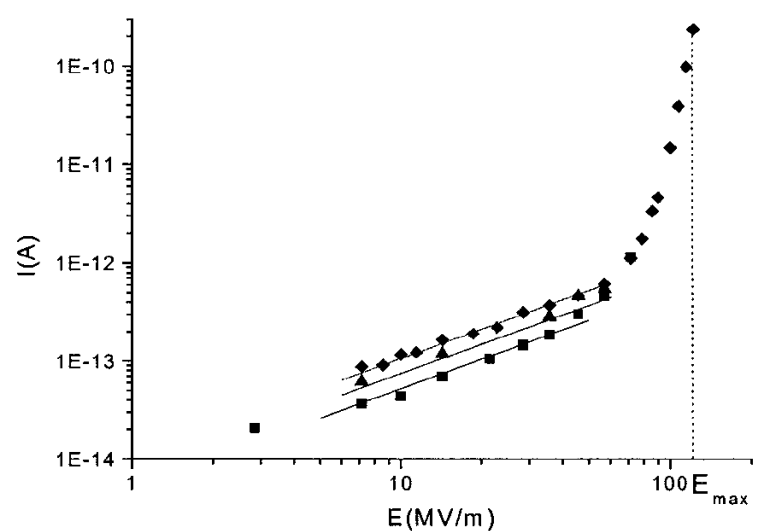

Fig. 5. Current-voltage characteristics for $70 \mu \mathrm{m}$ thich PEN films in amorphous state (diamond) and semi-crystalline state $(40 \%$ crystallinity) (square, triangle) [26].

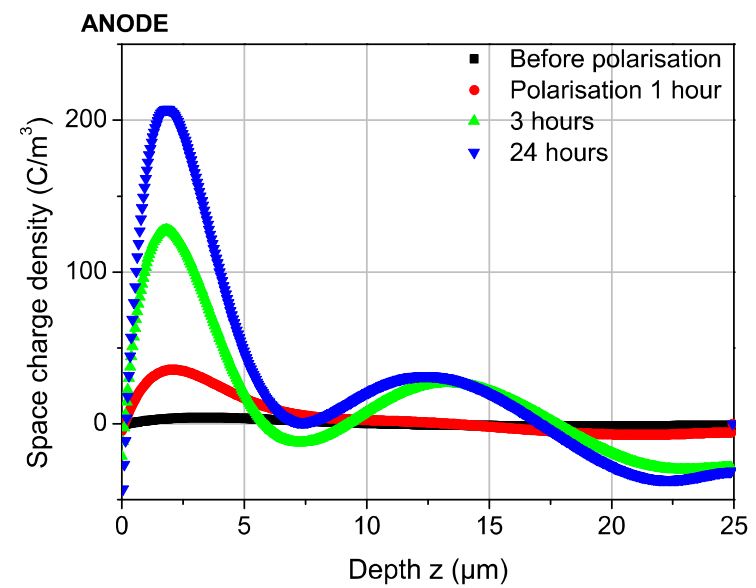

Fig. 6. Space charge profiles obtained by LIMM measurement on $25 \mu \mathrm{m}$ thick PEN after polarization under $200 \mathrm{kV} / \mathrm{mm}$ for different times. From [29]. Note that image charges are not detected by LIMM.

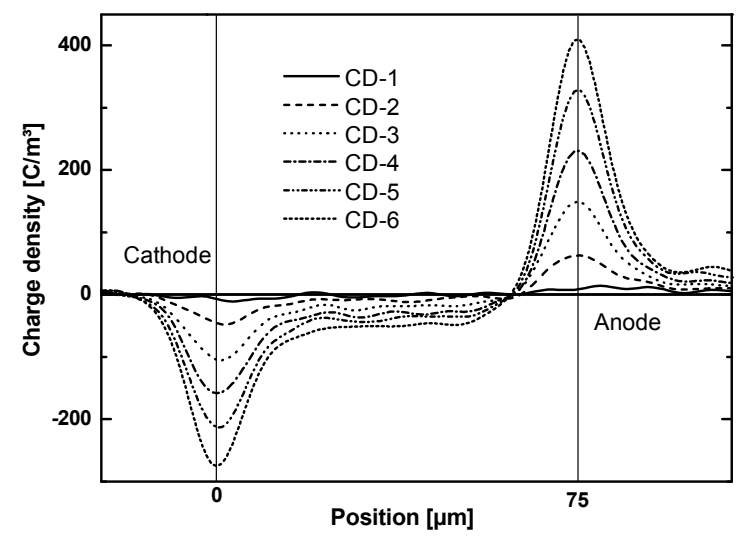

Fig. 7. Space charge profiles obtained on $75 \mu \mathrm{m}$ thick PEN film by PEA measurements under fast varying stress. Profiles correspond to different times during the $5 \mathrm{~ms}$ rising time from 0 to $200 \mathrm{kV} / \mathrm{mm}$ followed by a plateau. The period of signal is $50 \mathrm{~ms}$. From [30].

down the voltage, the characteristic is clearly not symmetrical: even though EL is still proportional to current for fields beyond $180 \mathrm{kV} / \mathrm{mm}$, the drop is faster than the rise. More importantly, a change of sign of the current is observed when the applied field is less than about $140 \mathrm{kV} / \mathrm{mm}$. Still with 


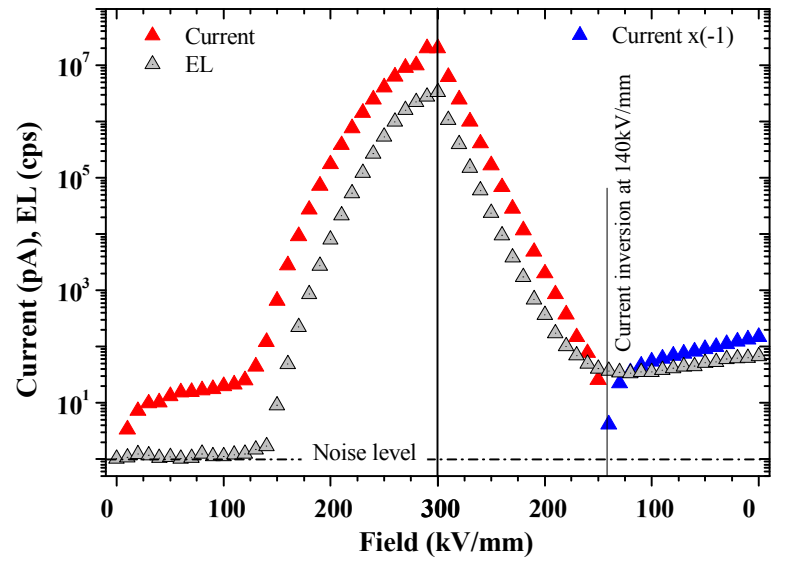

Fig. 8. EL and current vs. field characteristics obtained for a $25 \mu \mathrm{m}$ thick PEN at room temperature. A step-wise increase/decrease of the field was applied, with steps of $10 \mathrm{kV} / \mathrm{mm}$. The steps duration were $300 \mathrm{~s}$ in step-up and $150 \mathrm{~s}$ in step down. Reported current and EL data are averaged over the last $200 \mathrm{~s}$ in step-up and $100 \mathrm{~s}$ in step-down. The current is obtained for an electrode area of $20 \mathrm{~cm}^{2}$. A change of sign of the current occurred during step-down as indicated by vertical line.

decreasing the applied field, the EL tends to rise and reaches a steady value well above the noise level even at zero volts. These features are the sign that there is a slow release of previously generated charges, in large amount for inducing substantial field redistribution. The EL can be due to bipolar charge recombination if one resorts to some of the space charge patterns featuring homocharge build-up at each electrode, or to impact excitation if the field at the electrode is the driving process for current and EL. The monitoring of EL, current and EL spectrum for several days under high field indicated that strong field distribution occurs under DC stress [25]. The analysis of light decay following DC charging of the material indicated that charge recombination seems to be a major mechanism in EL excitation [31]. The memory effect of previous DC stressing on field-strain curves $[28,29]$ is a further mark of charge build up at high field in PEN.

\section{B. Electroluminescence under AC stress}

In view of the large space charge effects likely to occur in $\mathrm{PEN}$ at high fields, it is interesting to consider the case of $\mathrm{AC}$ stress. The effect of frequency on the EL phase patterns has been investigated along with the EL-field characteristics. A feature of EL under ac stress, not specific to PEN, is the occurrence of surface plasmons emission when using gold electrodes [32]. Recent characterization achieved using ITO electrodes allows getting rid of these effects [33]. Typically EL-field characteristics obtained on PEN are shown in Fig. 9. Compared to DC stress, the EL threshold is found at at a much lower field (about $30 \mathrm{kV} / \mathrm{mm}$ ), and the increase of the EL with field is much milder. The EL is in advance in respect to the peak voltage; the advance of phase tends to decrease with increasing the field (from $18^{\circ}$ to $9^{\circ}$ when going from 160 to $270 \mathrm{kV} / \mathrm{mm}$ ). The EL under $\mathrm{AC}$ is controlled by the recombination of injected carriers and trapped carriers with opposite charges. Injected charges either are trapped or recombine with trapped carriers of opposite polarity from last half field cycle, generating advance of EL peak. Compared to

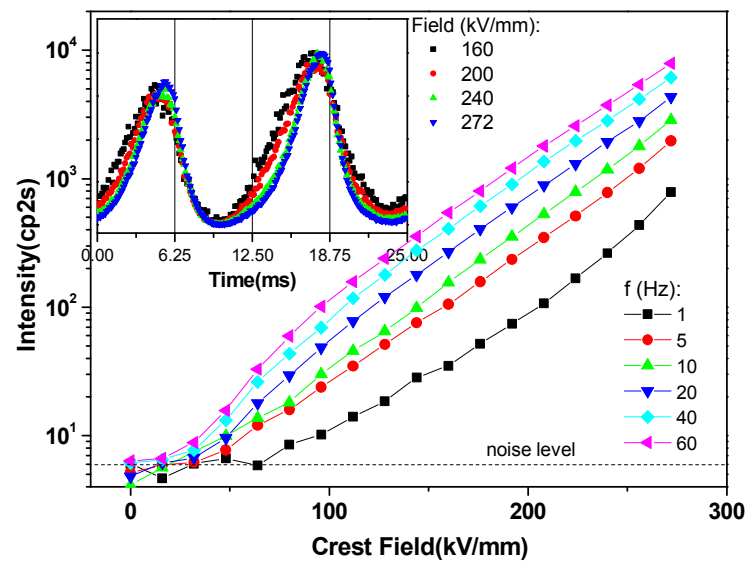

Fig. 9. EL-field characteristics under sine ac stress at different frequencies. In inset: EL phase patterns for $40 \mathrm{~Hz}$ frequency and different fields [33].

DC, AC-EL is presumably localized next to the electrode upon injection/extraction of charges. It is more sensitive to electrode nature and interface properties than DC-EL.

\section{Electroluminescence spectra}

We finally consider the spectral distribution of EL in PEN. A typical EL spectrum obtained with $25 \mu \mathrm{m}$ thick film provided with semitransparent silver electrodes is shown in Fig. 10 for different DC fields. The spectrum has been interpreted as constituted by 3 main contributions [10, 25]:

-Bands at 578 and $638 \mathrm{~nm}$ : They correspond to the phosphorescence of the material, cf. Fig. 3. The EL spectrum obtained at low temperature is clearly dominated by these two bands. The $638 \mathrm{~nm}$ band is probably overlapped by other contributions in EL spectra recorded at room temperature.

-Bands at 618 and $675 \mathrm{~nm}(620-680 \mathrm{~nm}$ in Fig. 9): Both strengthen, with respect to the phosphorescence of PEN, as the field increases. We detected an identical evolution of these two bands as a function of field, which means that they are probably paired. Note the shift by about $40 \mathrm{~nm}$ with respect to phosphorescence of PEN. They do not appear in the EL spectrum at low temperature. These bands most probably originate from the degradation: chemical groups derived from the polymer's structure would be formed.

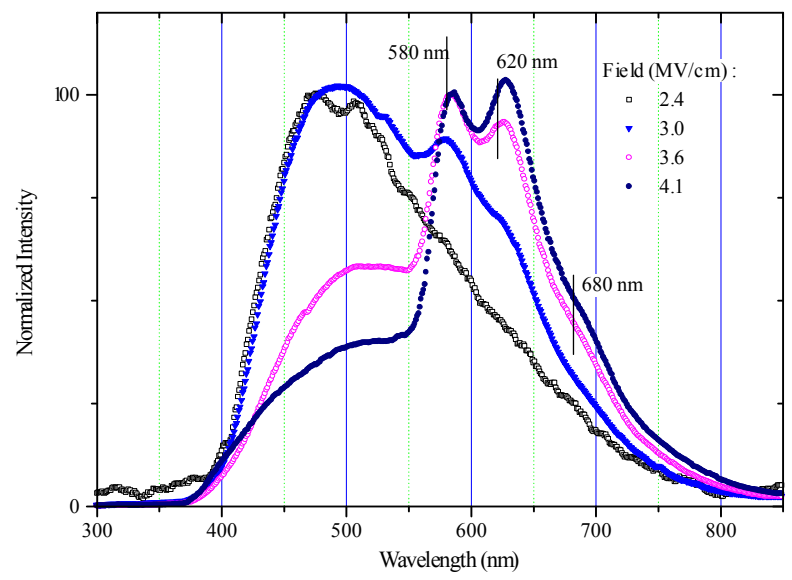

Fig. 10. EL spectra obtained under different DC fields in $25 \mu \mathrm{m}$ thick Ag-metallized PEN. 
-Band at $500 \mathrm{~nm}$ : It has been initially attributed to a tail of the fluorescence spectrum [8]. Its relative lowering for increasing field would be explained by quenching of excited states by the field: the excitons formed in the singlet state would be dissociated rather than relax. A problem is that its spectrum does not really match with the fluorescence of PEN. So an alternative would be that degradation products at the surface of PEN, as e.g. oxidized groups would be responsible for the emission. It would explain why this band tends to be larger under ac stress when the EL is more related to interface effects.

PL measurements on UV-aged PEN films showed the appearance of a new band in the region of $500 \mathrm{~nm}$ which corresponds to the EL spectrum at low field and so there is a possible common origin [10]. Its relative decrease as the field increases remains to be explained. Work is in progress for clarifying this behavior.

The evolution of the EL spectrum as a function of stressing time under $340 \mathrm{kV} / \mathrm{mm}$ has been exploited to infer the maximum field in the material [25]: the spectrum evolved as if the field was increasing. With considering the total EL variation, current as a function of time and EL spectrum shape evolution, we showed that the maximum field could exceed $400 \mathrm{kV} / \mathrm{mm}$ and that the charge density could be of the order of $300 \mathrm{C} / \mathrm{m}^{3}$ over $70 \%$ of the thickness after stressing continuously for several days. Such amounts are perfectly compatible with order of magnitudes of charge density given above.

The relation between EL spectrum shape and field magnitude is relatively well understood. However, the origin of the emission, particularly the longer wavelength doublet is not yet identified. The best reproduction of the EL spectrum has been obtained using electron beam irradiation, so-called cathodoluminescence -CL spectrum, cf. Fig. 11 [11]. Intense luminescence is obtained comparatively to EL; however the spectrum evolves quickly due presumably to degradation under impinging electrons. The evolution in time of the spectrum is similar to that obtained under applied field. The

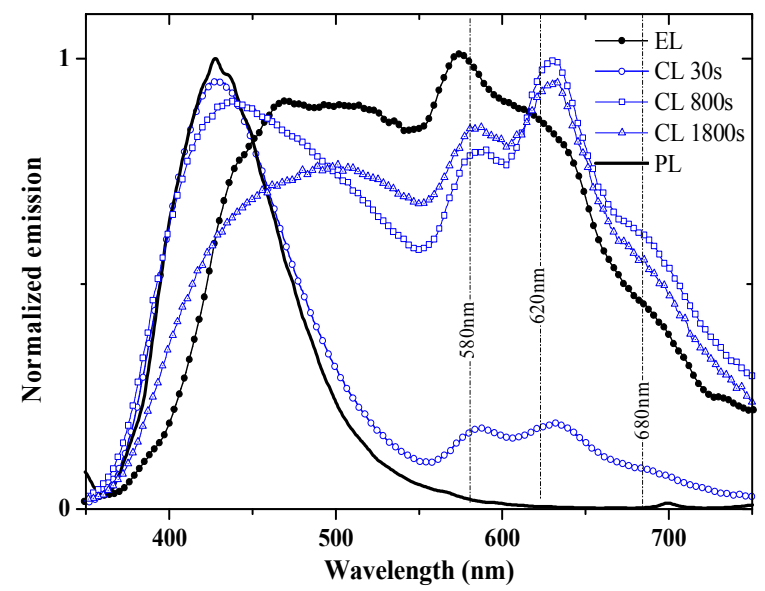

Fig. 11. Cathodoluminescence spectra (open symbols) under $10 \mathrm{keV}$ electron beam for 3 different irradiation times, EL spectrum (solid circles) under $250 \mathrm{kV} / \mathrm{mm}$ DC stress and photoluminescence spectrum (solid line) at room temperature. From [11]. main difference is that fluorescence is clearly detected at the beginning of the irradiation. The consistency of EL and CL spectra points to EL excitation by the impact of hot electrons.

\section{CONCLUSION}

We have reviewed works carried out by our group over the last 20 years about the behavior of Poly(ethylene naphthalate), particularly as regards the high field behavior. PEN is a good model material for its high field withstanding, for the coexistence of polarization and transport properties and for its relatively intense luminescence activity. We have given some evidence that at high fields space charges are settled into the material and impart to the material memory effects of electrical pre-stressing, through electroluminescence on one hand and through it electro-mechanical behavior on the other hand. A more complete characterization from the space charge standpoint at high field would be useful to discriminate between bipolar or unipolar space charge build-up.

Regarding ageing effects, we have touched the possibility that part of the signatures found in EL is related to ongoing chemical modification of the materials during excitation by an electric field. Identification of the nature of the emitting species would constitute a direct proof of electrical ageing process with a fingerprint of processes and by-products.

\section{REFERENCES}

[1] A.E. Tonelli, "PET versus PEN: what difference can a ring make," Polymer, vol. 43, pp. 637-642, 2002.

[2] P.M. Morse, "PEN: The new polyester", Chem. Eng. News, vol.75 (45), pp. 8-9, 1997.

[3] H. Nakamura, Y. Shirakawa, S. Takahashi, and H. Shimizu, "Evidence of deep-blue photon emission at high efficiency by common plastic", Europhys. Lett., vol. 95, n²2001, pp. 1-3, 2011.

[4] J. Garankin, A. Plukis, and R. Plukien, "Identification of particles of ionizing radiation by the analysis of fluorescence pulse form of the thin PEN film scintillator", IEEE Trans. Nucl. Sci., vol. 65, pp. 739-743, 2018.

[5] A. Laskarakis, "Study of the electronic and vibrational properties of poly(ethylene terephthalate) and poly(ethylene naphthalate) films," $J$. Appl. Phys., vol. 101, $\mathrm{n}^{\circ} 053503,2007$.

[6] P. Yang, F. Tian, and Y. Ohki, "Dielectric properties of poly(ethylene terephthalate) and poly(ethylene 2,6-naphthalate)", IEEE Trans. Dielectr. Electr. Insul., vol. 21, pp. 2310-2317, 2014.

[7] C. Cañadas, J. A. Diego, M. Mudarra, J. Belana, R. Dìaz-Calleja, M. J. Sanchis, and C. Jaimés, "Relaxational study of poly(ethylene-2,6naphthalene dicarboxylate) by t.s.d.c., d.e.a. and d.m.a.", Polymer, vol. 40, pp. 1181-1190, 1999.

[8] D. Mary, M. Albertini, and C. Laurent, "Understanding optical emissions from electrically stressed insulating polymers: electroluminescence in poly(ethylene terephthalate) and poly(ethylene 2, 6naphthalate) films", J. Phys. D.: Appl. Phys., vol. 30, pp. 171-184, 1997.

[9] G. Teyssedre, D. Mary, C. Laurent, and C. Mayoux, "Optical emission due to space charge recombination in insulating polymers: An insight into electrical ageing", in Space charge in solid dielectrics, Ed. J.C. Fothergill and L.A. Dissado, Dielectrics Society, Leicester, Chap.26, pp. 285-302, 1998.

[10] G. Teyssedre, D. Mary, and C. Laurent, "Electroluminescence and photoluminescence of UV-aged poly(ethylene naphthalate) films", IEE. Proc.-Sci. Meas. Technol., vol. 150, pp. 83-88, 2003.

[11] G. Teyssedre and C. Laurent, "Evidence of hot electron-induced chemical degradation in electroluminescence spectra of insulating polymers" Proc. Internat. Symp. Elect. Insul. Mater. (ISEIM), pp. 372375, 2008. 
[12] J.C. Cañadas, J. A. Diego, J. Sellarès, M. Mudarra, J. Belana, R. DìazCalleja, and M.J. Sanchis, "Comparative study of amorphous and partially crystalline poly(ethylene-2,6-naphthalene dicarboxylate) by TSDC, DEA, DMA and DSC", Polymer, vol. 41, pp. 2899-2905, 2000.

[13] L. Hardy, A. Fritz, I. Stevenson, G. Boiteux, G. Seytre, and A. Schönhals, "Dielectric relaxation behaviour of poly(ethylene naphthalene 2,6 dicarboxylate) (PEN)", J. Non-Cryst. Sol., vol. 305, pp. 174-182, 2002.

[14] B. Schartel and J. H. Wendorf, "Dielectric investigations on secondary relaxation of polyarylates: comparison of low molecular models and polymeric compounds", Polymer, vol. 36, pp.899-904; 1995.

[15] J.C. Coburn and R.H. Boyd, "Dielectric relaxation in poly(ethylene terephthalate)", Macromolecules, vol. 19, pp.2238-2245, 1986.

[16] C. Hakme, I. Stevenson, L. David, G. Boiteux, G. Seytre, and A. Schönhals, "Uniaxially stretched poly(ethylene naphthalene 2,6dicarboxylate) films studied by broadband dielectric spectroscopy", $J$. Non-Cryst. Solids, vol. 351, pp. 2742-2752, 2005.

[17] S.P. Bravard and R.H. Boyd, "Dielectric relaxation in amorphous poly(ethylene terephthalate) and poly(ethylene 2,6-naphthalene dicarboxylate) and their copolymers", Macromolecules, vol. 36, pp. 741748, 2003.

[18] T.A. Ezquerra, F. Balta-Calleja, and H.G. Zachmann, "Dielectric relaxation of amorphous random copolymers of poly(ethylene terephthalate) and poly(ethylene-2, 6-naphthalene dicarboxylate)", Acta Polym., vol. 44, pp. 18-24, 1993.

[19] J.J. Martinez-Vega, N. Zouzou, L. Boudou, and J. Guastavino, "Molecular mobility in amorphous and partially crystalline PEN after isothermal crystallization," IEEE Trans. Dielectr. Electr. Insul., vol. 8, pp. 776-784, 2001.

[20] M.Q. Hoang, L. Boudou, S. Le Roy, and G. Teyssedre, "Dissociating space charge processes from orientation polarization in Poly(ethylene naphthalate) films", J. Phys. D: Appl. Phys., vol. 47, n455306, 2014.

[21] D.H. Phillips and J. Schug, "Luminescence from aromatic polymers, monomers, and dimers under high energy electron excitation," J. Chem. Phys., vol. 50, pp. 3297-3306, 1969.

[22] N.S. Allen and J.F. McKellar, "Photochemical reactions in commercial poly(ethylene 2,6-naphthalate)", J. Appl. Polym. Sci., vol. 22, pp. 20852092, 1978 .
[23] H. Hashimoto, M. Hasegawa, K. Horie, T. Yamashi, H. Ushiki, and I. Mita", Fluorescence study of thermotropic liquid-crystalline polyesters" J. Polym. Sci.: Phys. Ed., vol. 31, pp. 1187-1196, 1993.

[24] P.S.R., Cheug, C.W. Roberts, and K.B. Wagener, "Synthesis, photodegradation, and energy transfer in a series of poly(ethylene terephthalate-co-2,6-naphthalenedicarboxylate) copolymers," J. Appl. Polym. Sci., vol. 24, pp. 1809-1830, 1979.

[25] G. Teyssedre, D. Mary, J.L. Augé, and C. Laurent. "Dependence of electroluminescence intensity and spectral distribution on ageing time in polyethylene naphthalate as modelled by space charge - modified internal field". J. Phys. D : Appl. Phys., vol. 32, pp. 2296-2305, 1999.

[26] J.F. Chavez, J.J. Martinez-Vega, N. Zouzou, and J. Guastavino, "Influence of morphology on electric conductance in poly(ethylene naphthalene-2,6-dicarboxylate)", Macromol. Symp., vol. 212, pp. 485490, 2004.

[27] J.L. Augé, G. Teyssedre, C. Laurent, T. Ditchi, and S. Holé. "Combined electroluminescence and charge profile measurements in Poly(ethylene2,6-naphthalate) under a DC field", J. Phys. D : Appl. Phys., vol. 33, pp. 3129-3138, 2000.

[28] T. Tran Anh L. Berquez, L. Boudou, and J. Martinez-Vega, "Effect of trapped space charge on mechanical deformation induced by electric field", IEEE Trans. Dielectr. Electr. Insul., vol. 18, pp. 1416-1422, 2011.

[29] G. Teyssedre, L. Berquez, and C. Laurent, "Some aspects of coupled electrical-mechanical effects in dielectric materials", Eur. Phys. J: Appl. Phys., vol. 70, n²0902, 2015.

[30] M. Fukuma, G. Teyssedre, C. Laurent, and K. Fukunaga. "Millisecondtime range analysis of space charge distribution and electroluminescence in insulating polymers under transient electric stress". J. Appl. Phys., vol. $98, \mathrm{n}^{\circ} 093528,2005$.

[31] G. Teyssedre, D. Mary, and C. Laurent. "Analysis of the luminescence decay following excitation of polyethylene naphthalate films by an electric field", J. Phys. D: Appl. Phys., vol. 31, pp. 267-275, 1998.

[32] L. Cisse, G. Teyssedre, D. Mary, and C. Laurent. "Influence of voltage frequency, the electrode material and a superimposed dc bias on ac electroluminescence of polymer films" IEEE Trans. Dielectr. Electr. Insul., vol. 9, pp. 124-129, 2002.

[33] B. Qiao, G. Teyssedre, and C. Laurent, "AC electroluminescence spectra of polyethylene naphthalate: impact of the nature of electrodes", Proc. IEEE Int. Conf. Electr. Insul. Dielectr. Phen., (CEIDP), pp. 93-96, 2013. 